\title{
Refraction microtremor (ReMi) to determine the shear wave velocity structure of the near surface and its application to aid detection of a backfilled mineshaft
}

\author{
Raines, M.G., D.A. Gunn ${ }^{1}$, Morgan, D.J.R., Williams, G. and Williams, J.D.O. \\ British Geological Survey, Kingsley, Dunham Centre, Keyworth, Nottingham, NG12 5GG
}

Caunt, $\mathbf{S}$.

The Coal Authority, 200 Lichfield Lane, Mansfield, Nottinghamshire, NG18 4RG

${ }^{1}$ Corresponding author.

\section{$\underline{\text { Abstract }}$}

Passive refraction microtremor (ReMi) surveys utilise standard field seismic-refraction recording equipment and linear geophone arrays to record ambient background noise due to microtremors caused by natural and anthropogenic activities. The technique relies upon the detection of coherent phases of Rayleigh waves that have propagated along the axis of the geophone array, which is the same mode of propagation that causes ground roll on standard refraction surveys. Rayleigh wave propagation is confined within one wavelength of the surface, causing dispersion because waves with longer wavelengths (lower frequencies) are controlled by ground stiffness and density properties at greater depths. Field records that include coherent modes of dispersive Rayleigh wave propagation along the field array are processed using slowness (reciprocal of the phase velocity)frequency transformations to extract the phase velocity-frequency dispersion curves. A series of dispersion curves are extracted by processing the field records of sub-groups including 6-8 geophones from which, 1D shear wave velocity-depth profiles are constructed and attributed to the centre of each array sub-group. In this survey, nine overlapping sub-groups of 8 geophones were selected along the whole field array of 24 geophones equi-spaced over $69 \mathrm{~m}$. A 2D shear wave velocity section was created by infilling a grid between each of the velocity-depths profile using an anisotropic inverse distance weighting algorithm. Interpretation of the $2 \mathrm{D}$ section included the identification of: reworked ground comprising colliery spoil and clay to around $5 \mathrm{~m}$ below ground level associated with shear wave velocities from $100-700 \mathrm{~m} / \mathrm{s}$; deeper strata within the host formation associated with higher velocities that increased in depth to above $1000 \mathrm{~m} / \mathrm{s}$ below $10 \mathrm{~m}$ bgl; a backfilled mineshaft and a backfilled sandstone quarry at depths below $7 \mathrm{~m}$ associated with low velocity perturbations within the background host velocity structure. Key recommendations from this case study include the use of low-frequency geophones to increase the depth of investigation and recording of high frequencies at reduced geophone spacings to increase near surface resolution. 


\section{$\underline{\text { Introduction }}$}

Microtremor is the name given to the background low-amplitude seismic waves that are present everywhere at the earth's surface. Microtremors with frequencies above 1 Hertz are generally associated with man-made, cultural sources (such as road traffic, trains, machinery, etc.), while those below 1 Hertz are generally associated with natural phenomena such as wind action and variations in atmospheric pressure (Okada 2003). Refraction microtremor (ReMi) is a surface geophysical measurement of the apparent phase velocities of Rayleigh waves propagating along a linear array of vertical geophones (Louie 2001). The true phase velocity is evaluated when wave propagation is parallel to the array, whereas propagation directions running obliquely to the array results in an apparent velocity which is an overestimation of the true velocity, (Louie 2001; Pullammanappallil 2003). The ReMi method transforms the time-domain velocity evaluation into the frequency domain and combines many arrivals over a long period of time allowing for easy recognition of dispersive surface waves. It is a type of microseismic survey (Aki 1957; Okada 2003) that utilises the Rayleigh wave component of ambient noise (passive sources) to obtain a shear wave velocity profile. Its potential use in the urban environment is highlighted by the fact that the Rayleigh waves may arise locally or regionally from traffic, water waves or wind shaking (Horike 1985). The method was developed originally for earthquake engineering purposes in response to the current costly techniques for assessing earthquake site response, namely spectral analysis of surface wave (SASW) and multi-channel analysis of surface wave (MASW), which both require large seismic sources to be effective. However other workers, notably Rucker (2003), now apply it routinely in their geotechnical engineering work, where projects have included interpreting depth to bedrock to support gravity studies; interpreting the base depth of an uncontrolled landfill; characterising foundation conditions at flood control dams and wind turbine sites; characterising subsurface profiles for tunnelling conditions at a major airport. Field data gathering requires the set-up of a linear array of geophones to record ambient seismic 'noise'. A surface-wave dispersion curve is derived and used to model sub-surface shear-wave velocity. The effective depth of investigation is related to the array length and geophone sensitivity. Generally, the maximum depth of investigation of between $1 / 3-1 / 2$ the array length is possible but can be limited by the low frequency sensitivity of the geophones, while near surface resolution is limited by the higher frequencies recorded. These surveys would have used relatively low frequency geophones $(8-14 \mathrm{~Hz})$ but, as an example of the versatility of this method, Rucker (2003) also used closely spaced high frequency 28-Hz geophones (mounted on large up-turned metal clips) inside a building to confirm poor ground compaction (in the top $3 \mathrm{~m}$ ) beneath a solid floor. More recently it has been applied in an urban environment on the construction of a new railway for the KTX (Korea Train eXpress), where it was used to determine 
the best tunnel route in tandem with a derived rock mass rating (Cha et al. 2006). The method is attractive for investigating the near surface $(<100 \mathrm{~m})$ for several reasons: field data can be collected efficiently using existing standard seismograph and vertical P - wave geophones as used in refraction studies; it requires no triggered source of wave energy; it works best in a seismically noisy urban setting, where vehicular traffic and cultural noise in general, provide the necessary surface waves that this method analyses; it can model velocity reversals with depth, unlike seismic refraction, which is inherently 'blind' to them and only practicable in normally dispersive ground conditions, i.e. velocity increasing with depth (Whiteley \& Greenhalgh 1979). This enables evaluation of complex ground velocity-depth profiles associated with the heterogeneity of disturbed ground, for example where a velocity reversal is caused by dislodged rock blocks with high velocities overlying less competent materials with low velocities.

This paper provides a case history detailing a refraction microtremor survey undertaken to assess the shear wave velocity structure about a backfilled, abandoned mineshaft at Brighouse, Yorkshire. The study is used to demonstrate the field application of ReMi to characterise the disturbance caused by the mineshaft via surveying and visualising the shear wave velocity structure within the host formation. The site near Brighouse, Yorkshire (Figure 1) was considered ideally suited to assessing the merits of the ReMi method, due to its proximity to the M62 urban sprawl. A single line of ambient noise or 'microtremor' measurements were recorded, producing a series of 1D shear-wave profiles down to $20 \mathrm{~m}$. From these, a 2D velocity/depth pseudo-section was constucted to determine the presence of a capped mineshaft and backfilled sandstone quarry. The measurements were taken during June 2005, at the end of the cross-borehole seismic tomography survey (Busby et al. 2005) and where earlier ground based geophysical techniques (ERT \& microgravity) had detected a capped shaft, interpreted to be back-filled (Busby et al. 2004). While the overall location of the mineshaft was known prior to surveying, excavations revealing the true morphology of the shaft were finally confirmed after the surveying was completed late 2005. These identified a brick lined shaft of approximately $3 \mathrm{~m}$ in diameter, backfilled with clay beneath approximately $1 \mathrm{~m}$ of made ground comprising colliery spoil and clay, Plate 1.

\section{Overview of Remi Methodology}

The refraction microtremor field technique is based on two fundamental ideas. Firstly, that common seismic-refraction recording equipment, set out in a way almost identical to shallow P-wave refraction surveys, can effectively record surface waves at frequencies as low as $2 \mathrm{~Hz}$ (Pullammanappallil et al. 2003). Although, the seismic source consists of ambient seismic 'noise', or microtremors, which occur constantly as cultural and natural background noise, successful field 
deployment requires the recording of coherent phases of dispersive Rayleigh waves that have propagated along the array. An example of this is the ground roll caused by nearby disturbances that induce vertical ground displacements (Figure 2a). Secondly, that a simple, two-dimensional slowness-frequency (p-f) transform of a microtremor record can separate Rayleigh waves from other seismic arrivals, and allow recognition of true phase velocity against apparent velocities. In simple terms, random ambient ground vibrations that propagate in the form of surface Rayleigh waves carry significant information about the velocity structure (and associated physical properties and geological character) of the subsurface. High frequency (short wavelength) vibrations have propagation characteristics governed by elastic properties of the near surface, while lower frequencies (longer wavelengths) are influenced by properties at greater depth.

ReMi data processing involves three steps: Velocity Spectral Analysis, Rayleigh Phase-Velocity Dispersion Picking, Shear Wave Velocity Modelling and is described in detail by Pullammanappallil et al. (2003). The basis of the velocity spectral analysis is the slowness-delay transformation, or "slantstack," described by Thorson \& Claerbout (1985). Multiple seismogram records are allocated into a space-time matrix, where each row is the amplitude-time variation on each geophone at successive offsets along the array. The number of rows depends upon the number of geophones used in the analysis, which could include the whole array to provide an averaged velocity profile at the array centre or sub-groups of between $6-8$ geophones to provide velocity profiles at the subarray centres. The time delay between a signal on the seismogram of the first geophone and equivalent signals on the successive records in the group is used with the spacing between the geophones to calculate a delay velocity or its reciprocal, the slowness, as illustrated in the inset in Figure 2b. Performing a Fourier transform on the slowness-delay matrix provides a matrix of slowness (or it reciprocal, velocity) against frequency. The slowness-frequency analysis also produces an indication of the distribution of the spectral intensity within the slowness-frequency space. High intensity mapping with low velocities along the frequency axis is identified as Rayleigh wave fundamental mode propagation, Figure $2 \mathrm{~b}$. The dispersion curve for the Rayleigh wave can be picked from the transformation of the field noise record, where the shear-wave velocity is a simple factored fraction of the Rayleigh wave velocity, usually 0.9 (Horike 1985; Menzies 2001; Okada 2003). For a Rayleigh wave propagating axially along a linear geophone array, the phase-velocity dispersion curve is selected upon the basis of the envelope of maximum spectral energy (Figure 2c). However, to avoid an over-estimation of the phase-velocity of waves propagating obliquely to the geophone array, the low velocity limit of the envelope of the maximum spectral energy is often picked. The dispersion curve is then interactively forward-modelled to determine the subsurface shear-wave velocity profile (Figure $2 \mathrm{~d}$ ). The solutions provided are non-unique (i.e. more than one 
profile model can produce the same dispersion curve) and for this reason, inversion techniques use a first tentative profile of the site and adjust it by comparing the results of the numerical simulation to the dispersion curve obtained from the field test (Tokimatsu et al. 1992; Yuan \& Nazarian 1993). The simplest method is attribution of a factored shear wave phase-velocity to a depth equivalent to a fraction of the Rayleigh wavelength, $\lambda$. Fractional factors range from $\lambda / 4$ to $\lambda / 2$ (Jones 1958; Ballard \& McLean 1975; Abbis 1981). Gazetas (1982) recommended that $\lambda / 4$ be used where the stiffness increases significantly with depth and that $\lambda / 2$ is used for more homogeneous stiffness profiles, but a factor of $\lambda / 3$ is most commonly used. More computationally involved inversion includes the production of a state vector describing the interface properties between each layer in the model, which are defined by a transfer matrix. Propagation matrices are also determined, which describe how the seismic waves are transmitted through the layered model. Each of the transfer matrices is converted into a series of equivalent stiffness matrices, which are combined into a global stiffness matrix for the complete soil profile, from which a theoretical dispersion curve is calculated. The model iterates on phase velocity at each period (or frequency) and reports when a solution has not been found within the iteration parameters. The detail of the inversion is beyond the scope of this paper, but thorough descriptions can be found in Thomson (1950), Haskell (1953) and Kausel \& Roesset (1981). Available inversion software includes SURF by Herrmann (1998) and WinSASW by Joh (1996; 2002).

The above ReMi processing steps can be undertaken on the signals from different groups of geophones, provided that the surface wave contains sufficient energy across the full spectrum of interest to ensure information isn't lost within the depth profile; e.g. near surface information lost due to attenuation of higher frequencies. The resulting velocity-depth profiles are then attributed to a location at the centre of the geophone group used in the processing; groups comprising as few as 6 geophones can be used. Figure 2d shows velocity-depth profiles constructed using a simple $\lambda / 3$ inversion of the field dispersion curves derived via a continuous surface wave survey (Gunn et al. 2006) and via ReMi survey using a group of eight geophones. This example demonstrates the deterioration that occurs with the near-surface information due to low strength high frequency signals, while the lower frequency information compare well below a depth of $2 \mathrm{~m}$. Other workers report good correlation between Re-Mi velocity-depth profiles and borehole velocity logs (Louie, 2001). 


\section{Microtremor Survey at Brighouse}

\section{Survey Setup}

Figure 3 shows the layout and orientation of the $72 \mathrm{~m}$ long ambient noise array in relation to the site buildings and the backfilled mineshaft. Several boreholes were also drilled about the mineshaft for the purposes of various tomographic surveys (Busby et al. 2005). The aim of the ReMi survey was to cover sufficient ground with the view to establishing the representative shear wave velocity of intact Lower Coal Measures towards the northwest end, the backfilled shaft material in the middle of the array and the buried quarry fill at the south eastern end. An array spread was required to ensure sufficient numbers of geophones (e.g. 6 to 8) could be sub-grouped over ground that was away from the disturbed zones about the shaft and the quarry. This enabled evaluation of the velocities of low frequency (15 to $20 \mathrm{~Hz}$ ) waves propagating in relatively undisturbed Lower Coal Measures. A 24geophone array using 10-Hertz vertical geophones at $3 \mathrm{~m}$ separation was set up approximately equidistant about the southeast boundary wall and ensuring at least one of the geophones (No. 10) was centred over the mineshaft. At each position, a small hole was dug and the geophone inserted to approximately $75 \mathrm{~mm}$ below the surface and then covered with soil and/or turf (Plates 2a \& 2b).

\section{Site Geology}

The site geology comprises colliery spoil and clay (re-worked ground), which overlies a zone of sandstone, siltstones and mudstones where the sandstone and siltstones are identified by relatively high electrical resistivities and the mudstones by relatively low electrical resistivities on the well logs for boreholes 1 and 5, (see Figure 4). Generally, the colliery spoil and clay extend to approximately $2 \mathrm{~m}$ depth across the site. Underlying this is a zone is an interval to approximately 12 - $14 \mathrm{~m}$ depth, mainly comprising mudstones with either a gradation into siltsones or, incorporating a wedge of siltstones within them occurring over to the west where the siltstones are identified as having greater electrical resistivities than the mudstones. This is indicated by the electrical log in borehole 5 between $7 \mathrm{~m}$ to $10 \mathrm{~m}$ in Figure 4 . Below this, extending to approximately $16-18 \mathrm{~m}$ depth is a zone predominantly comprising sandstone with siltstone. Coal bearing mudstones and siltstones lie beneath this, extending to depths beyond $20 \mathrm{~m}$. The Huddersfield Memoir indicates the generalised dip of the strata be of the order of 10 to 15 degrees towards an E or an ENE direction (Addison et al. 2005). The increase in depth by a few metres of the higher resistivity sandstonesiltstone zone from borehole 5 towards borehole 1 is broadly in keeping with the lower limit of the generalised dip. 


\section{Data Acquisition and Processing}

A standard ABEM Terraloc Mk 5, 24 channel seismograph was positioned towards the middle of the array (Plate 2b) and set up with a 2 milliseconds sample interval and maximum recording time of 5 seconds. A hammer at the northwestern end of the array triggered each recording, and on at least $50 \%$ of the recordings. Use of an older series seismograph limited our records to 5 seconds, whereas 15-30 second recordings can be gathered with modern equipment, enabling greater noise energy levels to be recorded. Time limitations to the field records partly resulted in there being very low levels of high frequency energy in the ambient noise, which was overcome additional high frequency energy being introduced into the ground by the two operatives running towards the centre of the array during the 5 second recording. We suspect that some wind vibrating the local trees and traffic on the nearby A 643 would have increased the high frequency energy levels. While not introduced from a single source such as a hammer on plate, local noise generated in this manner, does ensure wave propagation along the array. A total of twelve ambient noise recordings each 5 seconds long, were made with no filtering and at a variety of gain settings. Field data processing was undertaken as outlined in the above ReMi methodology section using SeisOpt ReMi TM v3.0 by Optim LLC, USA (2003). The processing was undertaken on groups of 8 geophones and the resultant shear wave velocity-depth profiles plotted at the mid-point of each geophone grouping as detailed in Table 1 below. While the slowness-frequency transform improves with the no. of geophones in the subgroup, it performed poorly with sub-groups of less than 6 geophones where artefacts caused by spatial aliasing limit high frequency picking (Figure 5). Louie (2001) and Pullammanappallil et al. (2003) also report similar artefacts, so sub-groups of 8 geophones were chosen to balance survey resolution with processing performance.

\begin{tabular}{|l|c|c|}
\hline $\begin{array}{l}\text { Geophone } \\
\text { Series } \\
\text { (@ 3m centres) }\end{array}$ & $\begin{array}{l}\text { Distance interval (m) } \\
\text { along array }\end{array}$ & $\begin{array}{l}\text { Plot position (m) } \\
\text { on 2D image }\end{array}$ \\
\hline $\boldsymbol{G 1}$ - G8 & $0-21$ & 10.5 \\
\hline $\boldsymbol{G 3}-\mathbf{G 1 0}$ & $6-27$ & 16.5 \\
\hline $\boldsymbol{G 5}-\mathbf{G 1 2}$ & $12-33$ & 22.5 \\
\hline $\boldsymbol{G 7}-\mathbf{G 1 4}$ & $18-39$ & 28.5 \\
\hline $\mathbf{G 9}-\mathbf{G 1 6}$ & $24-45$ & 34.5 \\
\hline $\boldsymbol{G 1 1}-\mathbf{G 1 8}$ & $30-51$ & 40.5 \\
\hline $\boldsymbol{G 1 3}-\mathbf{G 2 0}$ & $36-57$ & 46.5 \\
\hline $\boldsymbol{G 1 5}-\mathbf{G 2 2}$ & $42-63$ & 52.5 \\
\hline $\mathbf{G 1 7}-\mathbf{G 2 4}$ & $48-69$ & 58.5 \\
\hline
\end{tabular}

TABLE 1. List of the geophone series used in processing microtremor data and in the construction of the $2 \mathrm{D}$ velocity pseudo-section. 


\section{Survey Results}

Survey geophones of 10 Hertz frequency were used to record ambient noise, enabling resultant shear-wave velocities to be evaluated to a depth of $20 \mathrm{~m}$. Shear-wave velocity profiles for each of the 8-geophone groupings are shown in Figure 6. In general an increase in shear-wave velocity is seen from the near surface ( $100 \mathrm{~m} / \mathrm{s}$ ) within the re-worked ground comprising colliery spoil and clay rising to $500-700 \mathrm{~m} / \mathrm{s}$ between $5-6 \mathrm{~m} \mathrm{bgl}$, within the zone of siltstones, sandstones and mudstones. In most geophone groupings, a velocity increase to $\sim 1000 \mathrm{~m} / \mathrm{s}$ is observed from a depth of around $14 \mathrm{~m}$ within the lower zone of sandstones and siltsones to $20 \mathrm{~m}$ within the coal bearing strata. The exception to this is grouping G7-G14, where this increase to $\sim 1000 \mathrm{~m} / \mathrm{s}$ occurs at the shallower depth at approximately $7 \mathrm{~m}$. A 2D shear-wave velocity pseudo-section was constructed using Geosoft software (Figure 7) and colour contoured ranging from light green (200 - $550 \mathrm{~m} / \mathrm{s}$ ) through to red $(>1000 \mathrm{~m} / \mathrm{s})$. The light green clearly marks out the low velocity re-worked ground comprising clay and colliery waste, whilst beneath this the dark green - mustard yellow colour scale (750-950 m/s) depicts the vertical backfilled shaft between stations $32 \mathrm{~m}$ and $38 \mathrm{~m}$ and edge of the backfilled (to a depth of $\sim 13 \mathrm{~m}$ ) sandstone quarry in the adjacent pasture field from station $53 \mathrm{~m}$ (see Plate 2a). Apparent solid and intact ground with velocities $>1000 \mathrm{~m} / \mathrm{s}$ was observed below a depth of $7 \mathrm{~m}$ adjacent and to the north west of the shaft between stations $24 \mathrm{~m}$ to $32 \mathrm{~m}$, i.e. within the lower zone of mudstones and siltstones and extending into the underlying sandstones and siltstones, and coal bearing strata. In contrast, there appeared to be a low velocity zone present between 7 - 10 $\mathrm{m}$ bgl from stations $10-20 \mathrm{~m}$. It is possible that this zone may have been excavated and later backfilled as a part of the engineering works related to the former colliery railway line that ran across the NW end of the line. Lateral resolution could be improved by a combination of decreasing the geophone spacing and processing further geophone groups. Table 1 indicates the interpretation was made with a total of 9 sets of 8-channel geophone groups out of the 17 available; for example, 8-channel groups beginning at even numbered geophones could have been processed. An apparent advantage of this method over seismic refraction is observed in Figure 6, where small velocity reversals are noted between 5 - 6 m below ground level on geophone groupings G9 - G16 through to G17 - G24 respectively. Reversals in the velocity-depth profiles occur in layered sections when materials with greater velocities overly those with lower velocities. In this case, the upper, fast layer is represented by a velocity of around $600 \mathrm{~m} / \mathrm{s}$, overlying a slower layer of around $400 \mathrm{~m} / \mathrm{s}$. Such a profile at this site could be associated with weathered sandstone overlying degraded mudstone or coal shale, for example such as in boreholes 1 and 9 at about $4 \mathrm{~m}$. As a general guide the minimum thickness for layers can be related to the difference in wavelengths calculated between incremental 
frequencies. An example in this case would be a difference of $0.5 \mathrm{~m}$ between wavelengths at 50 and $52 \mathrm{~Hz}$ with a velocity of $600 \mathrm{~m} / \mathrm{s}$.

\section{Conclusions}

Operating with standard refraction seismic equipment, using the relatively new refraction microtremor (ReMi) method, a single line of ambient noise or 'microtremor' measurements was made at a site where an abandoned mineshaft was known to exist. 24 geophones of 10 Hertz frequency spaced at $3 \mathrm{~m}$ along a $72 \mathrm{~m}$ array were used to record microtremors and resultant Rayleigh waves propagating to a depth of $20 \mathrm{~m}$. Contoured shear velocity data shown in the $2 \mathrm{D}$ velocity section of Figure 7 suggests that the method has successfully mapped relatively low velocity structures beneath the made ground/colliery waste (5 - $6 \mathrm{~m}$ thick) that are associated with the backfilled mineshaft and edge of the former sandstone quarry.

The results of this survey provide a useful case history to demonstrate the potential of this technique, particularly for use in the urban environment. To ensure robust analysis of the field records, the method requires noise data from at least six geophones but our experience indicated that processing groups of eight geophones improved results. The depth of investigation is partly controlled by the lowest frequencies that can be recorded by the geophones. Thus, it is recommended that lowfrequency geophones be used for these surveys, e.g. $10 \mathrm{~Hz}$ or even $4 \mathrm{~Hz}$ geophones. If the survey objective requires the identification of a small specific target such as a buried mineshaft rather than a profile indicating the general 2D lateral variation in velocity, then greater resolution can be achieved by using a smaller geophone spacing (e.g. $0.5-1.0 \mathrm{~m}$ ) as well as processing and plotting data from all the geophone groups. The method has identified a backfilled mineshaft, but is not recommended where there is a cavity or open air-filled shaft greater than $3 \mathrm{~m}$ in diameter beneath the surface. This is because little or no noise transmission reaches the geophones, although that in itself may be diagnostic. The versatility of the method is demonstrated by its ability to investigate a range of subsurface depths from shallow $(<3 \mathrm{~m})$ to deep ground $(<100 \mathrm{~m})$, by simply decreasing the geophone frequency and increasing the spacing. The ReMi method can determine velocity reversals with depth, unlike seismic refraction. Potential field survey measurement and processing time of about four hours per $100 \mathrm{~m}$ array, makes this a very efficient method for investigating variations in shear-wave velocity in the near and shallow subsurface. This method appears contrary to most other geophysical techniques in that it works best in a culturally noisy urban environment. However, if there is little or no noise present, then it has to be created by driving, running or walking along the geophone array, but it should be stressed that coherent surface wave phases must be present within the 'noise', which is the case when introducing localised noise in this manner. While it was beyond 
this current study, there is scope for further development of field practices employing methods of introducing energy from linear sources and also from several point sources incrementally spaced along the geophone array.

\section{Acknowledgements}

This article is published with the permission of the Executive Director of the British Geological Survey (NERC). The authors gratefully acknowledge the financial support of The Coal Authority (Contract Ref: CA 18/C1251). Finally, the authors thank Mr. Mick Lever for access to the site during the survey trials at Brakehead Cottage.

\section{$\underline{\text { References }}$}

Abbiss, C.P. 1981. Shear wave measurements of the elasticity of the ground. Geotechnique, 31, (1), pp91-104.

Addison, R., Waters, C.N. \& Chisholm, J.I. 2005. Geology of the Huddersfield district: a brief explanation of the geological map. Sheet Explanation of the British Geological Survey, 1:50000 Sheet 77, Huddersfield (England \& Wales).

Aki K., 1957. Space and time spectra of stationary stochastic waves, with special reference to microtremors. Bull. Earthquake. Res. Inst. Tokyo, 35, 415-457.

Ballard, R.F. \& McLean, F.G. 1975. Seismic field methods for in situ moduli. Proc. Conf. on In Situ Measurement of Soil Properties. Spec. Conf. Geotech. Eng. Div., A.S.C.E., Vol 1, pp121-150.

Busby, J. P., Beamish, D., Chambers, J., Gofton, J. C., Ogilvy, R. D., Wilkinson, P. B., Raines, M. G., Morgan, D. J. R. and Weller, A. L. 2004. Surface geophysical mapping of an abandoned mineshaft, Brake Head, Site D. A report for the Coal Authority, contract CA18/C1251. British Geological Survey Commissioned Report CR/04/277. 29 p.

Busby, J. P., Chambers, J., Gunn, D. A., Binley, P. B., Wilkinson, P. B., Raines, M. G., Ogilvy, R. D. and Weller, A. L. 2005. Cross-hole tomographic imaging of a back-filled mineshaft, Brake Head, Site D. A report for the Coal Authority, contract CA18/C1251. British Geological Survey Commissioned Report CR/05/173. $42 \mathrm{p}$.

Cha, Y. H., Kang, J. S. and Jo, C, H. 2006. Application of linear-array microtremor surveys for rock mass classification in urban tunnel design. Exploration Geophysics 37, 108-113.

Gazetas, G. 1982. Vibrational characteristics of soil deposits with variable velocity. Int. Jour. Numerical and Analytical Methods in Geomech., Vol 6, pp 1-20.

Gunn, D.A., L.M. Nelder, J.E. Chambers, M.R. Raines, H.J. Reeves, D. Boon, S. Pearson, E. Haslam, J. Carney, A.B. Stirling, G. Ghataora, M. Burrow, R.D. Tinsley, W.H. Tinsley, R. Tilden-Smith, 2006. Assessment of railway embankment stiffness using continuous surface waves. Proc. $1^{\text {st }}$ Int. Conf. Railway Foundations, Birmingham, September 2006, pp94-106.

Haskell N.A. 1953. The dispersion of surface waves on multilayered media. Bull. Seismological Society of America, vol. 43, (1), pp 17-34.

Herrmann R. 1998. Computer programs in seismiology-manual. Univ. St. Louis, USA. www.eas.slu.edu 
Horike, M. 1985. Inversion of phase velocity of long-period microtremors to the $\mathrm{S}$ wave-velocity structure down to the basement in urbanized areas, J. Phys. Earth, 33, 59-96

Joh, S.-H. 1996. FIT7: Program for forward modelling analysis, inversion analysis and time trace generation. University of Texas, USA.

Joh, S.-H. 2002. WinSASW Version 2.0. Data interpretation and analysis for SASW measurements. User's guide. Dept. Civil Engineering, Chung-Ang University, Korea.

Jones, R.B. 1958 In-situ measurement of the dynamic properties of soil by vibration methods. Geotechnique, vol. 8 (1), pp. 1-21.

Louie, J, N. 2001. Faster, Better: Shear-wave velocity to 100 meters depth from refraction microtremor arrays. Bull. Seismological Soc. Am., v. 91, p. 347-364.

Kausel E. \& Roesset J.M. 1981. Stiffness matrices for layered soils. Bull. Seismological Society of America, vol. 71 (6), pp 1743-1761.

Menzies, B.K. (2001) Near-surface site characterisation by ground stiffness profiling using surface wave geophysics. Instrumentation in Geotechnical Engineering. H.C.Verma Commemorative Volume. Eds. K.R. Saxena and V.M. Sharma. Oxford \& IBH Publishing Co. Pvt. Ltd., New Delhi, Calcultta. pp 43-71.

Okada, H. 2003. The microtremor survey method. Geophysical Monograph Series No. 12, Society of Exploration Geophysicists. Tulsa. USA. 127 p.

Optim L. L. C. 2003. SeisOpt ReMi v2.0 for Windows 95/98/00/NT/Me/XP, Optim Software and Data Services, UNR-MS-174, 1664 N. Virginia St., Reno, Nevada, 89557.

Pullammanappallil, S., Honjas, W. and Louie, J, N. 2003. Determination of a 1-D shear wave velocities using the refraction microtremor method. Proc. $3^{\text {rd }}$ Int. Conf. Application of Geophysical Methodologies and NDT to Transportation and Infrastructure, December 8-12, 2003, Orlando, Florida, USA.

Rucker, M. L. 2003. Applying the refraction microtremor (ReMi) shear wave technique to geotechnical characterisation. Proc. $3^{\text {rd }}$ Int. Conf. Application of Geophysical Methodologies and NDT to Transportation and Infrastructure, December 8-12, 2003, Orlando, Florida, USA.

Thomson W.T. 1950. Transmission of elastic waves through a stratified solid medium. J. Applied Physics, vol. 21 (1), pp 89-93.

Thorson, J. R., \& Claerbout, J. F. 1985.Velocity-stack and slant-stack stochastic inversion. Geophysics, 50, pp. 2727-2741

Tokimatsu K., Tamura S. \& Kojima H. 1992. Effects of multiple modes on Rayleigh wave dispersion characteristics. Jour. Geotech. Eng., ASCE, vol. 118, (10), pp. 1529-1543.

Whiteley, R.J. \& Greenhalgh, S.A. 1979. Velocity inversion and the shallow seismic refraction method. Geoexploration, 17, pp125-141.

Yuan D. \& Nazarian S. 1993. Automated surface wave method: inversion technique. Jour. Geotech. Eng., ASCE, vol. 119, (7), pp 1112-1126. 


\section{List of Figures:}

Figure 1 Location of ambient noise geophone array (G1 - G24) in relation to Brakehead Cottage and former sandstone quarry. Ordnance Survey Topography @ Crown copyright. Licence number: 100017897 / 2006

Figure 2. ReMi processing steps from field record to shear wave velocity profile.

a. 36 channel field record: Coherent phase Rayleigh wave (ground roll) propagation.

b. Phase velocity (1 / Slowness)-frequency transform of field record.

c. Field dispersion curve picked from the velocity-frequency transform.

d. Velocity-depth profiles for single location: Microtremor - mid-point 8 channel field record; CSW - mid-point source - 4 channel array (CSW - Continuous surface wave method described by Menzies 2001).

Figure 3. ReMi geophone array relative to buildings, mineshaft and boreholes.

Figure 4. Lithological and electrical resistivity logs indicating the generalised host geological structure.

Figure 5. High frequency picking limited on slowness (1/velocity) frequency image by aliasing artefact.

Figure 6 Plots of shear velocity (m/s) versus depth for geophone groups, G1-G8, G3-G10, G5-G12 \& G7G14 (top); G9-G16, G11-G18, G13-G20, G15-G22 \& G17-G24 (bottom).

Figure 7 2D - Pseudo-section of contoured shear wave velocity data from geophone groupings shown in Figure 6.

Plate 1. Backfilled mineshaft identified by brick lining approximately $3 \mathrm{~m}$ in diameter under approximately 1 $\mathrm{m}$ of spoil cover.

Plate 2. ReMi field survey set-up relative to the site buildings and mineshaft.

a. northwest along microtremor array from Geophone 24

b. southeast along microtremor array 


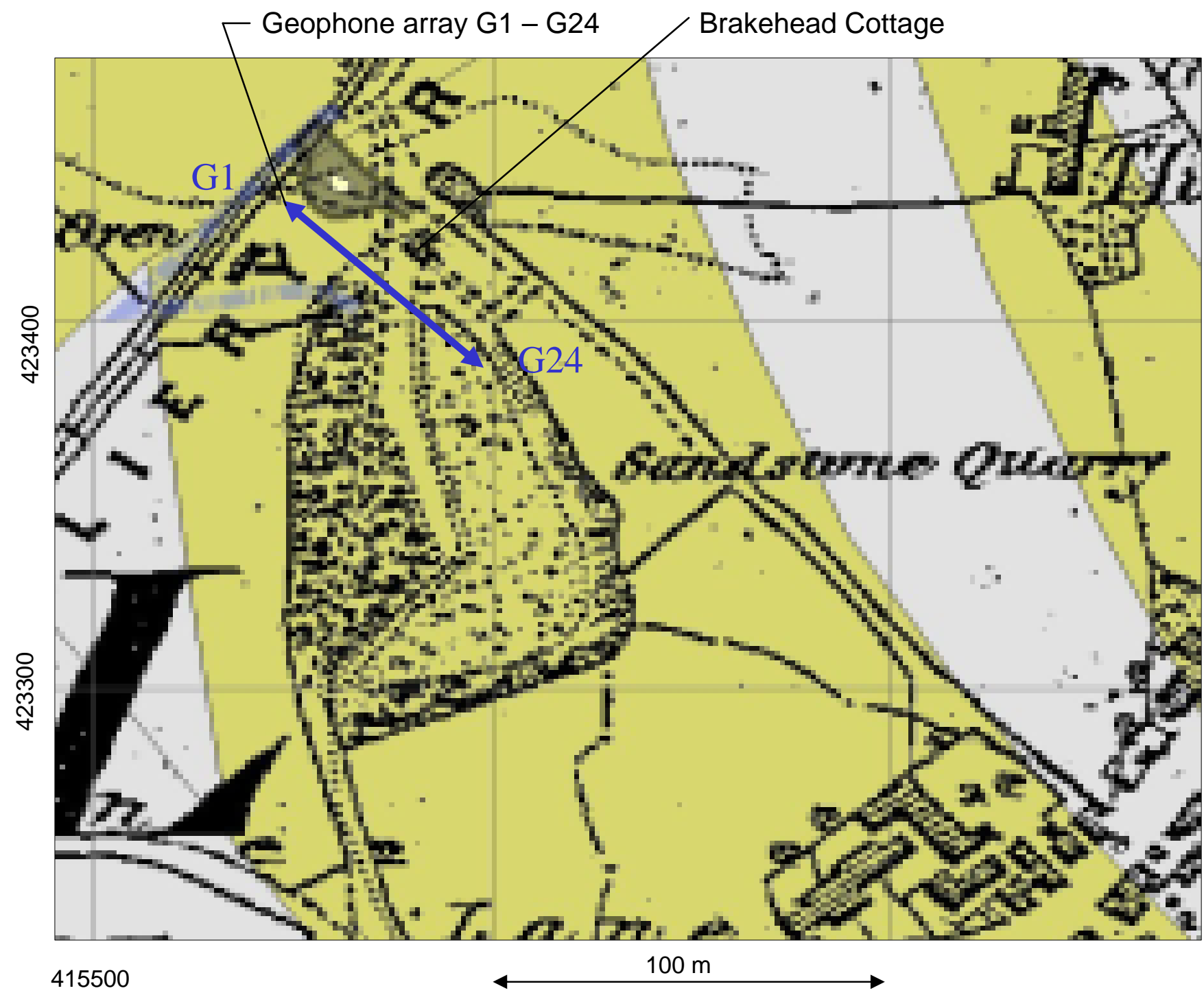

Figure 1 Location of ambient noise geophone array (G1 - G24) in relation to Brakehead Cottage and former sandstone quarry. Ordnance Survey Topography @ Crown copyright. Licence number: 100017897 / 2006 


\section{Time ( seconds )}

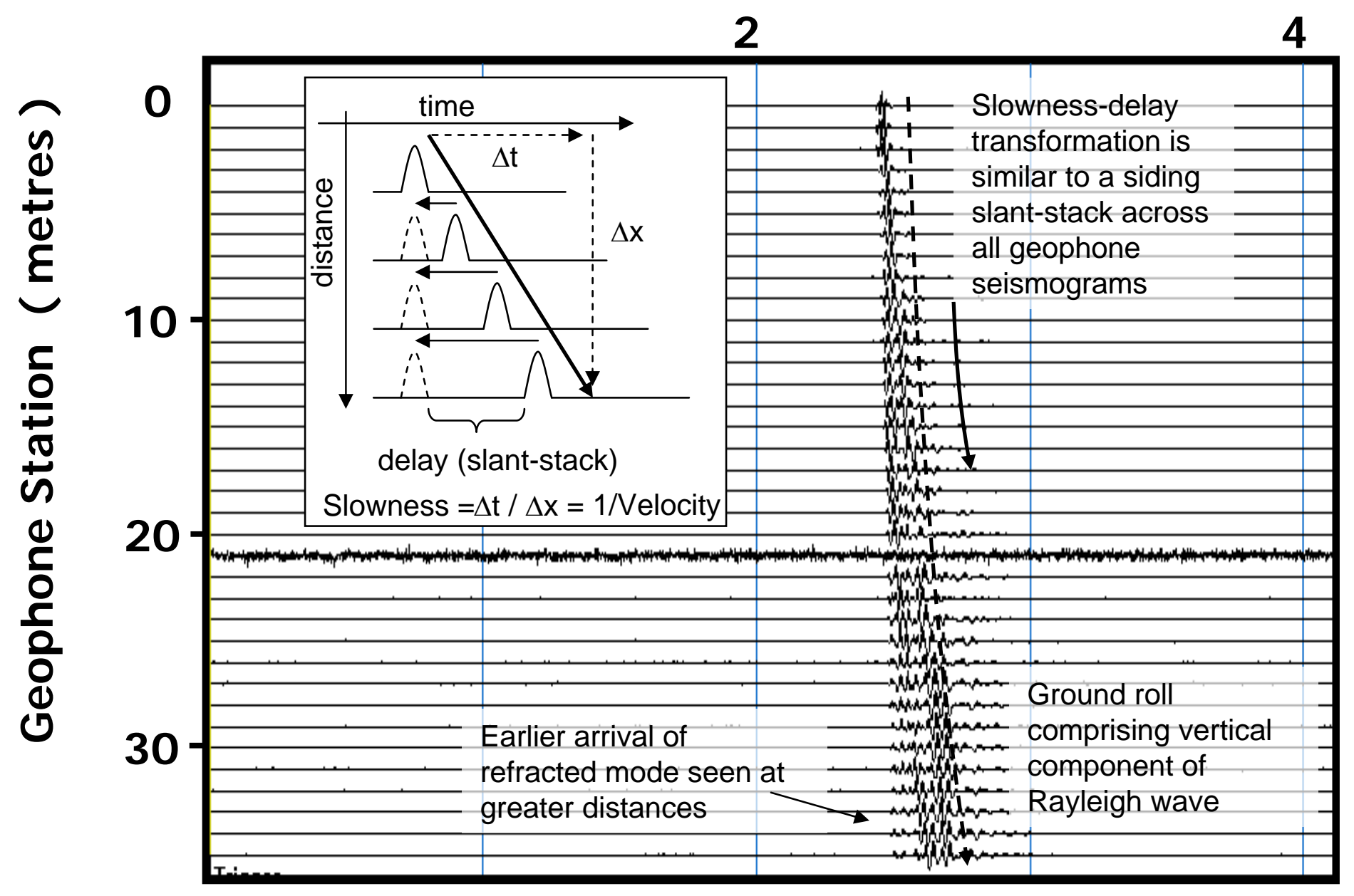

a. 36 channel field record: Coherent phase Rayleigh wave (ground roll) propagation.

Figure 2. ReMi processing steps from field record to shear wave velocity profile. 


\section{Phase Velocity ( $\mathrm{m} / \mathrm{s})$}

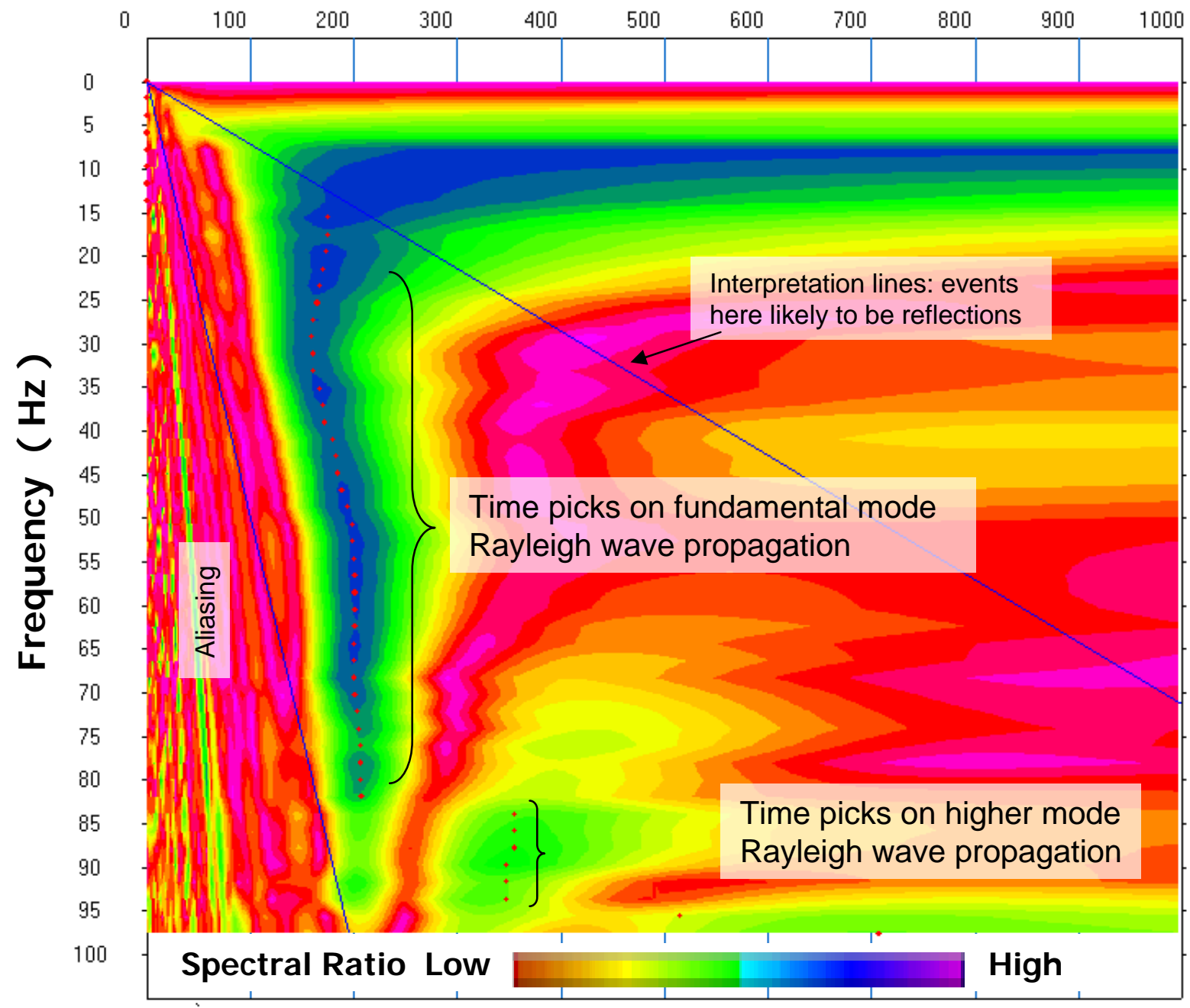

b. Phase velocity (1 / Slowness)-frequency transform of field record.

Figure 2. ReMi processing steps from field record to shear wave velocity profile. 
Frequency $(\mathrm{Hz})$

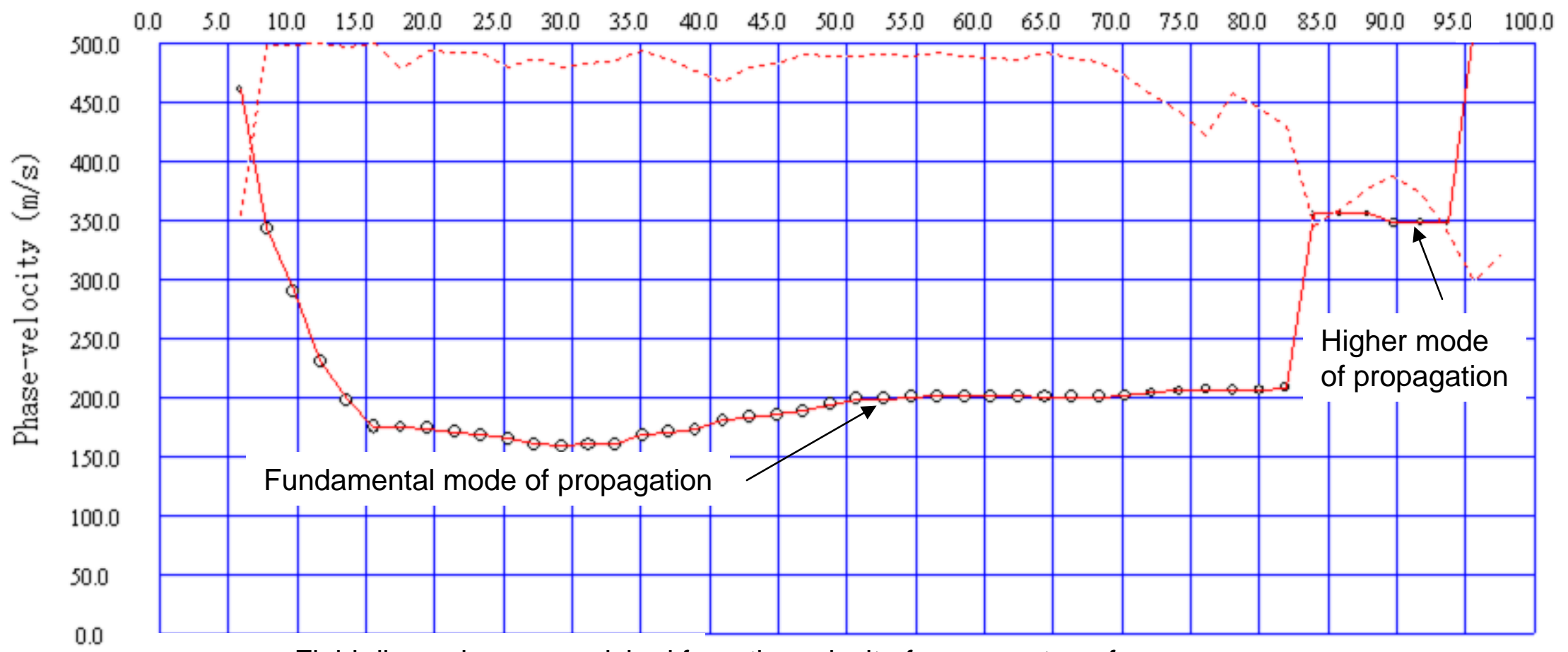

c. Field dispersion curve picked from the velocity-frequency transform.

Figure 2. ReMi processing steps from field record to shear wave velocity profile. 
Shear Wave Velocity $(\mathrm{m} / \mathrm{s})$

d. Velocity-depth profiles for single location: Microtremor - mid-point 8 channel field record CSW - mid-point source -4 channel array (CSW - Continuous surface wave method described by Menzies 2001).

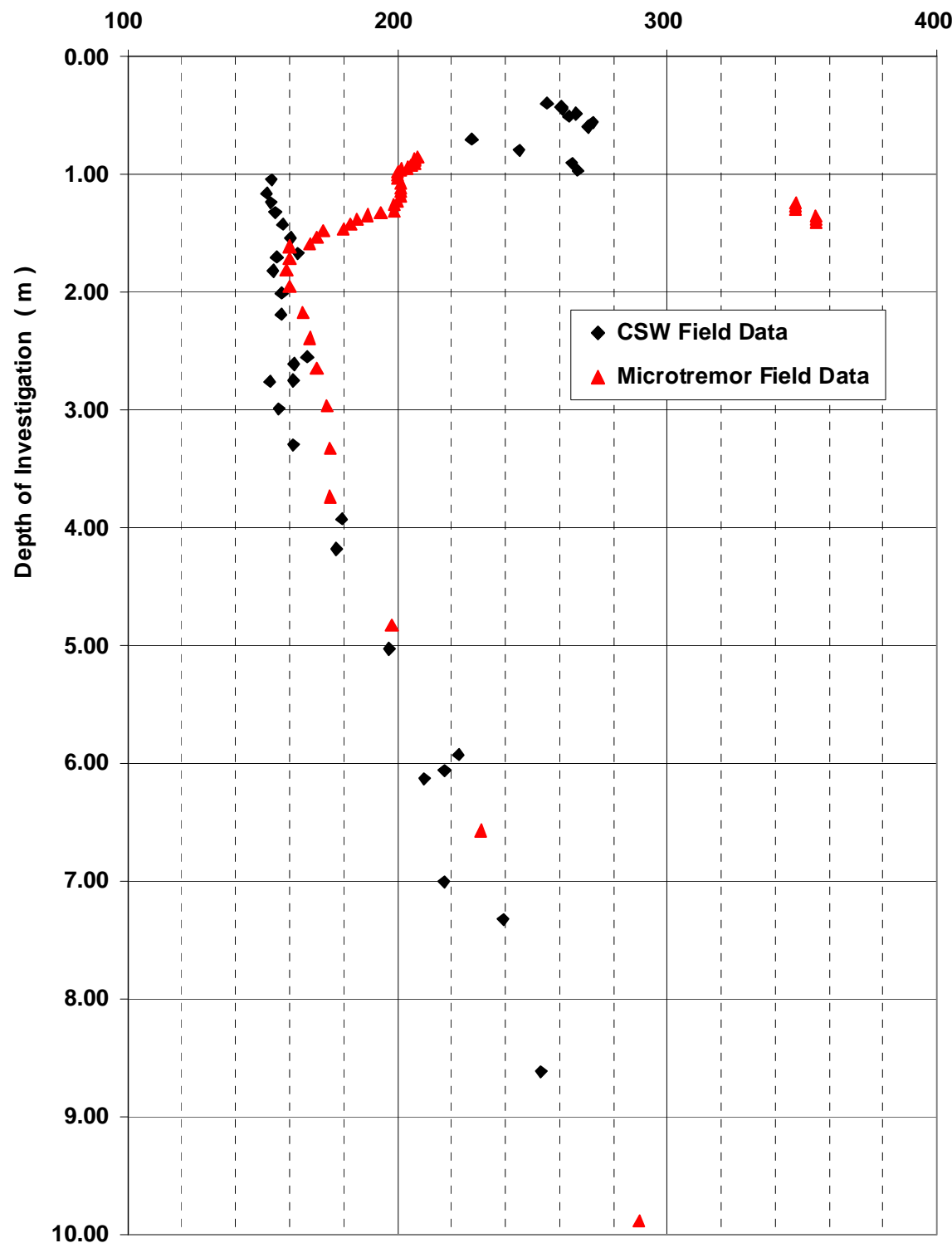

Figure 2. ReMi processing steps from field record to shear wave velocity profile. 


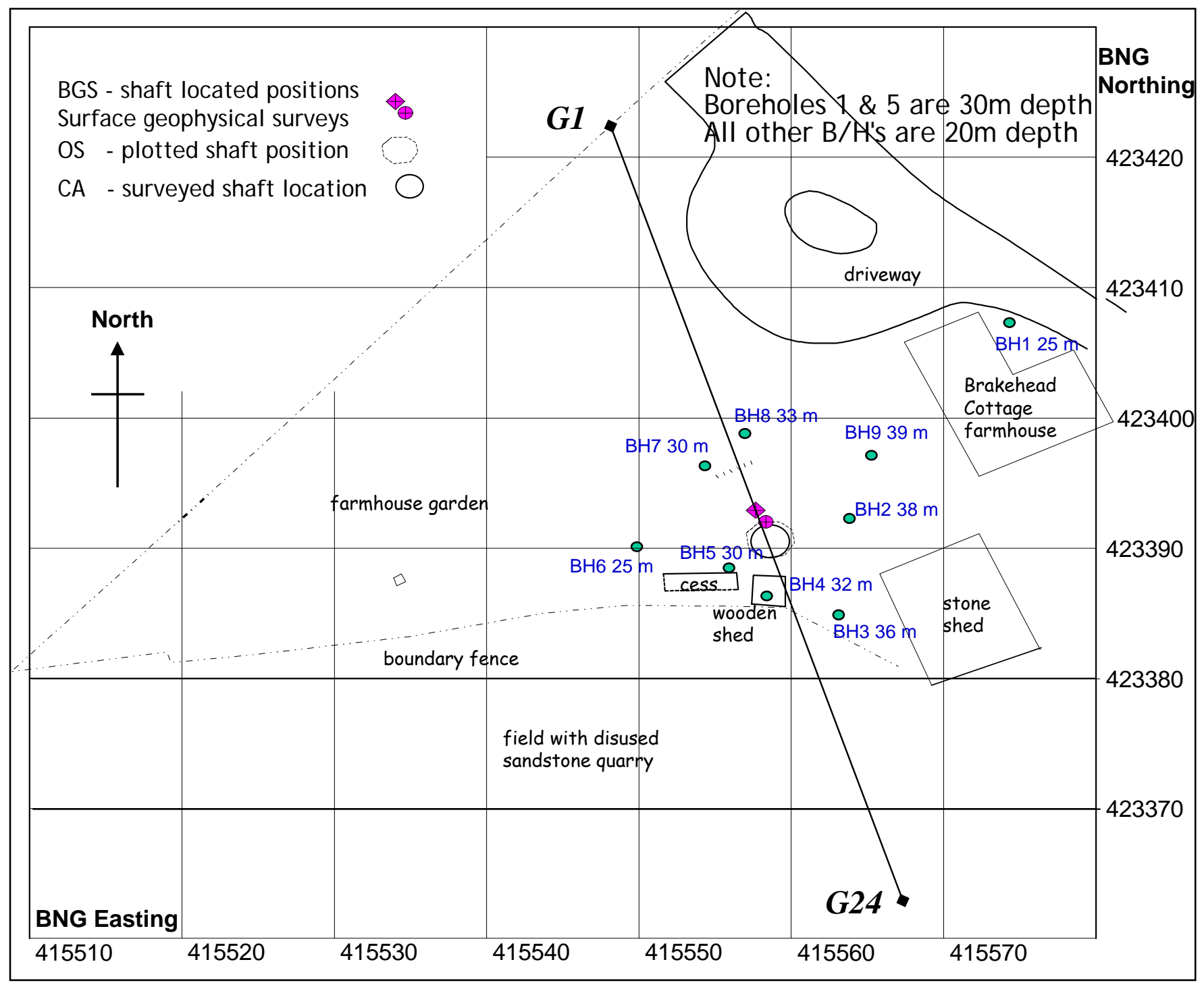

Figure 3. ReMi geophone array relative to buildings, mineshaft and boreholes. 


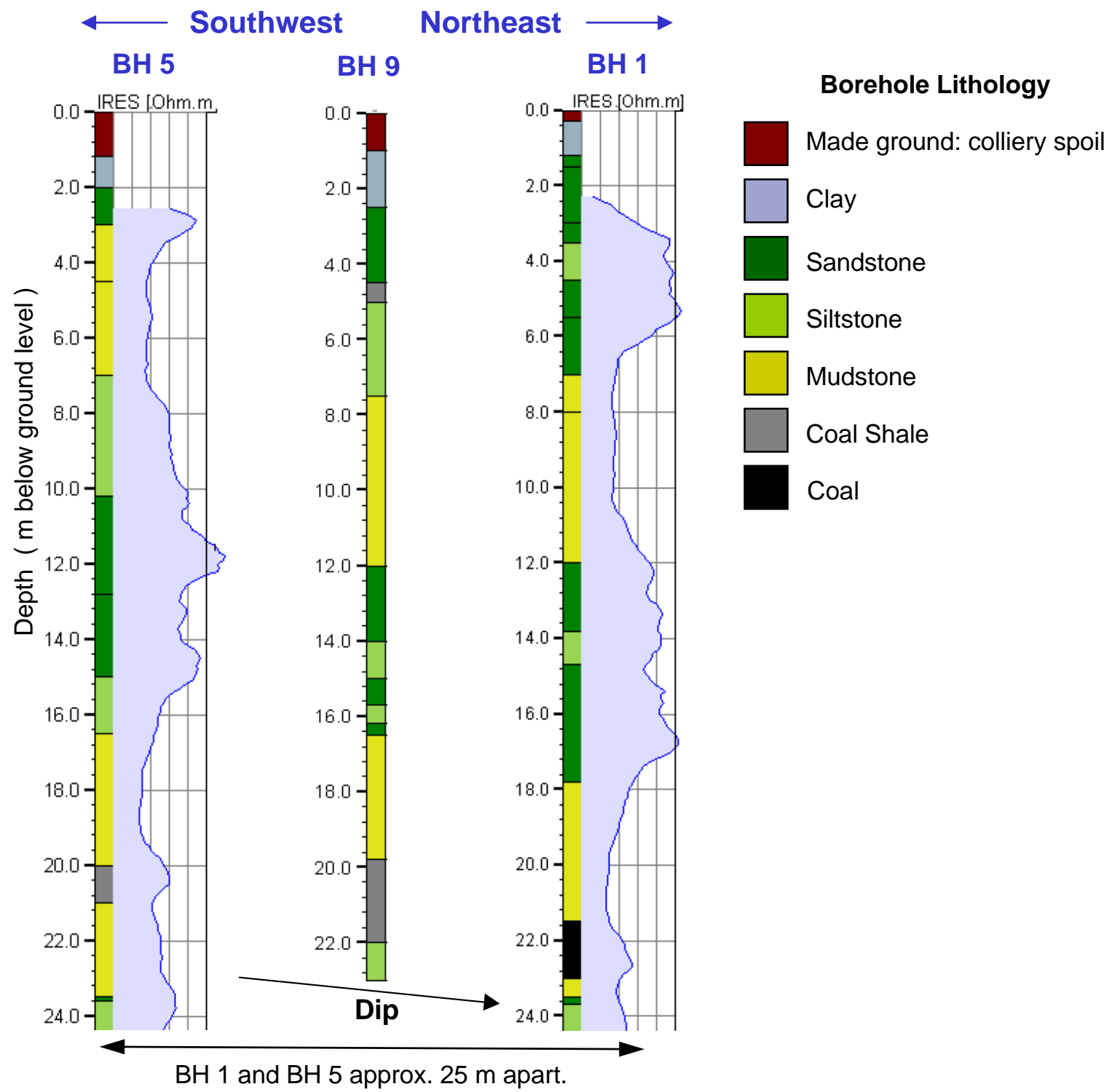

Figure 4. Lithological and electrical resistivity logs indicating the generalised host geological structure. 


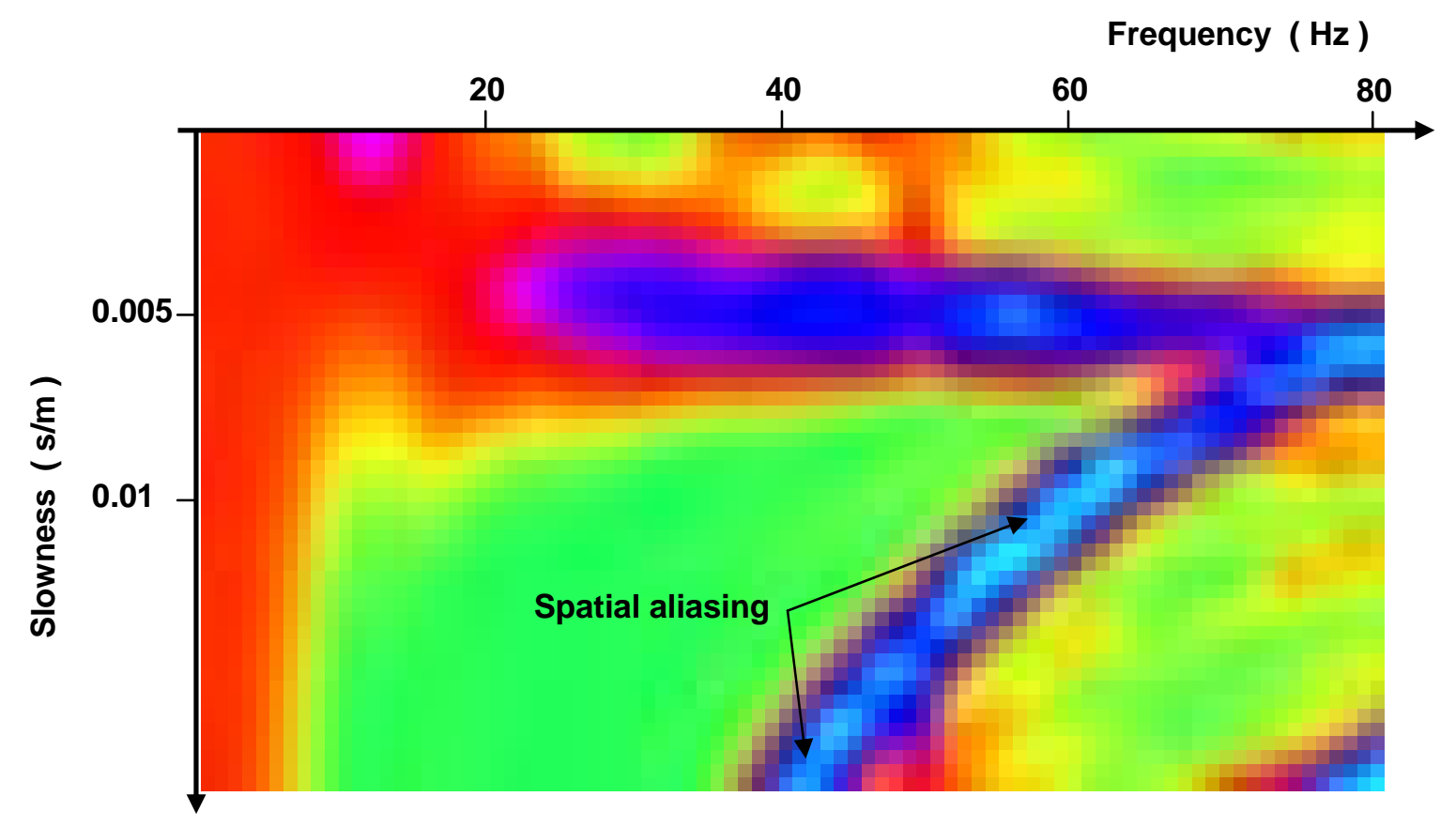

Figure 5 High frequency picking limited on slowness (1/velocity) frequency image by aliasing artefact. 


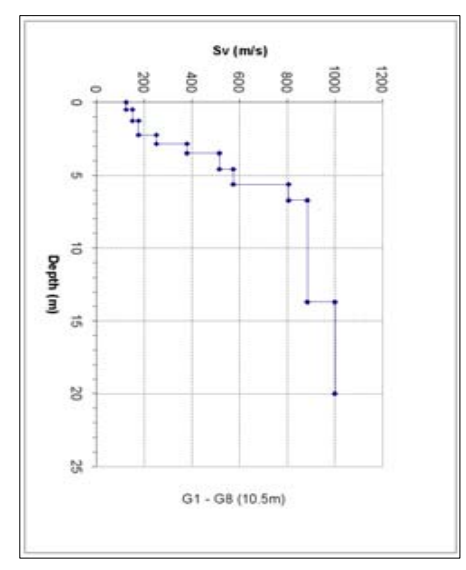

G1-G8

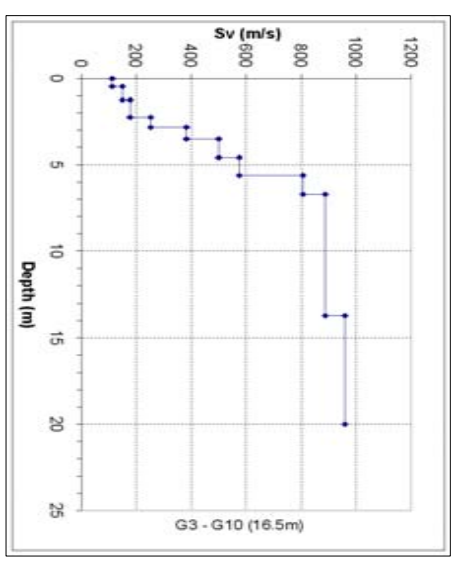

G3-G10

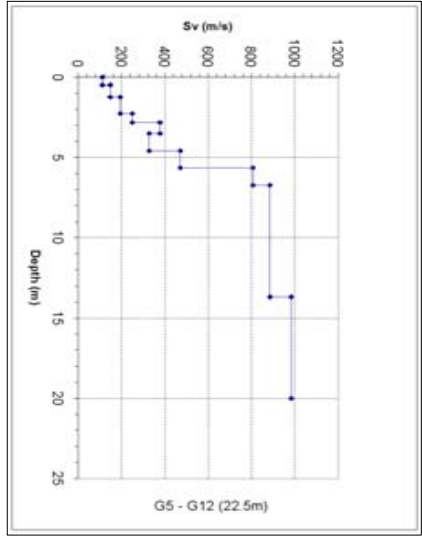

G5-G12

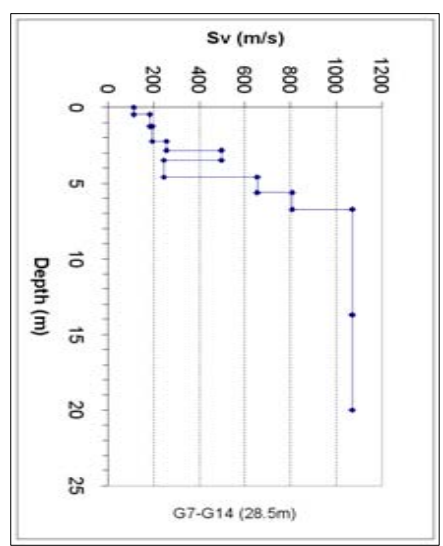

G7-G14

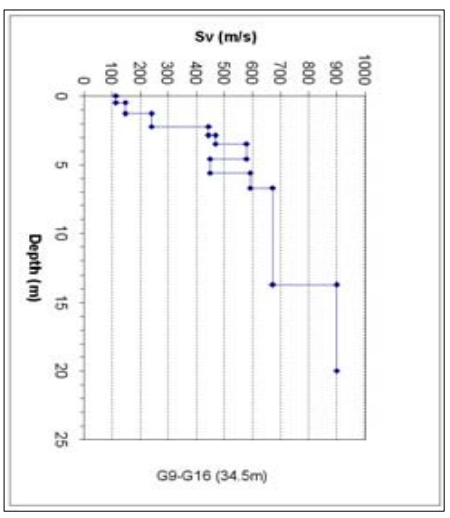

G9-G16

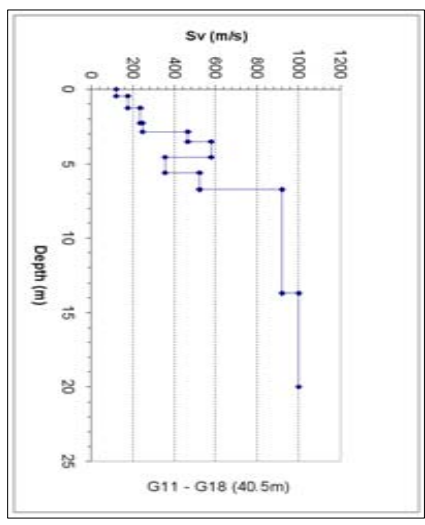

G11-G18

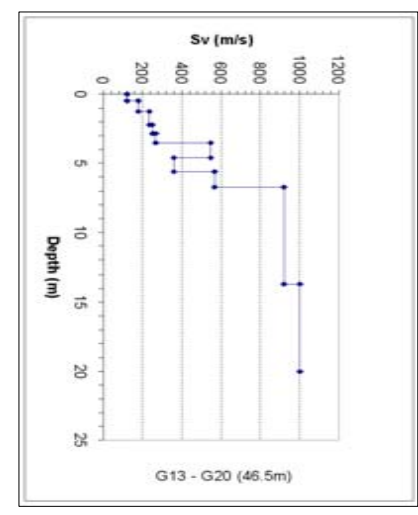

G13-G20

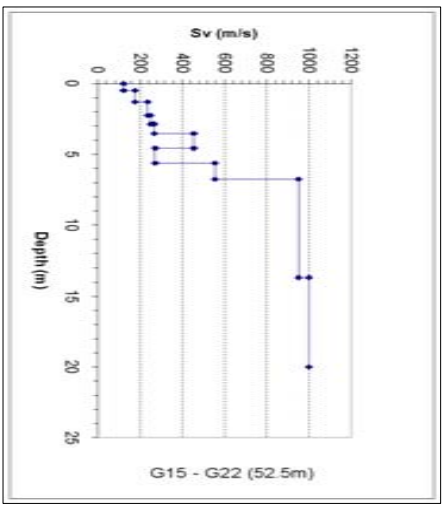

G15-G22

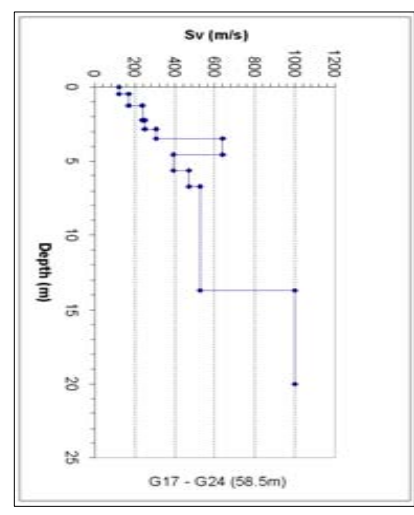

G17-G24

Figure 6 Plots of shear velocity (m/s) versus depth for geophone groups, G1-G8, G3-G10, G5-G12 \& G7-G14 (top); G9-G16, G11-G18, G13-G20, G15-G22 \& G17-G24 (bottom). 
Relatively low velocity comprising $\sim 2 \mathrm{~m}$ of made ground and colliery waste overlying weathered Coal Measures to $\sim 5 \mathrm{~m}$

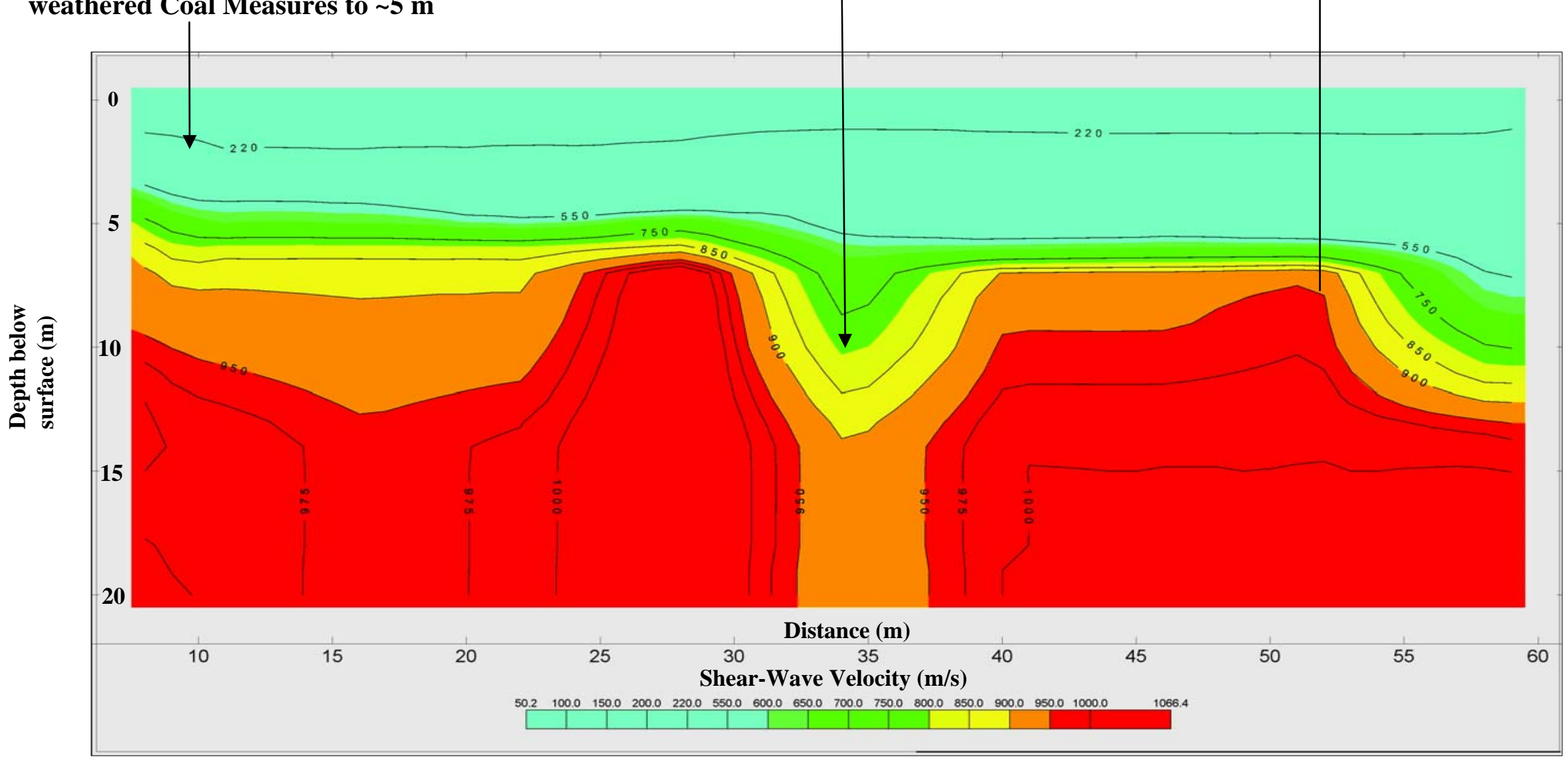

Figure $72 \mathrm{D}$ - Pseudo-section of contoured shear wave velocity data from geophone groupings shown in Figure 6. 


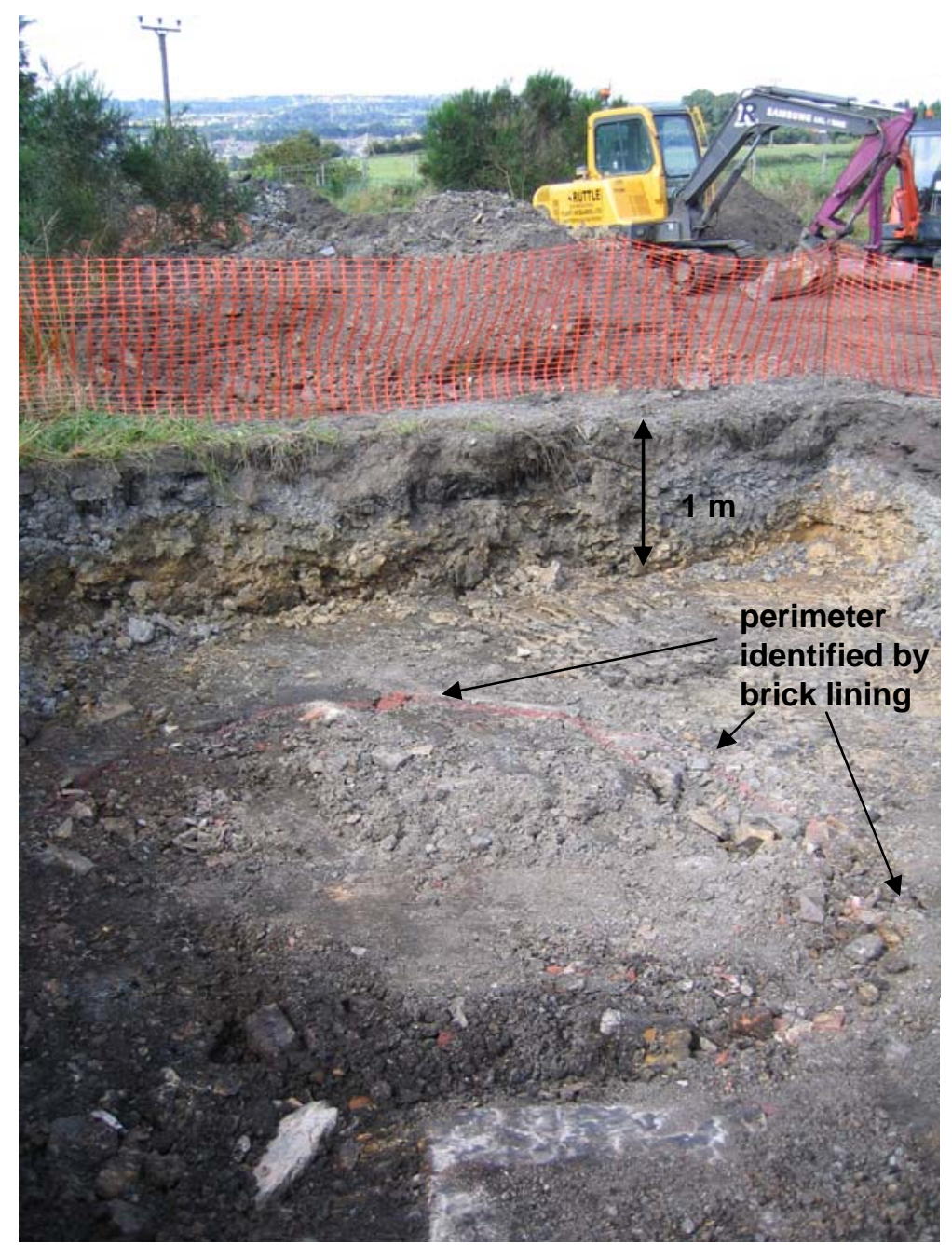

Plate 1 Backfilled mineshaft identified by brick lining approximately $3 \mathrm{~m}$ in diameter under approximately $1 \mathrm{~m}$ of spoil cover. 
